\title{
EL CHACO BOREAL EN EL CONTEXTO TRANSNACIONAL ACTUAL: LA RESPONSABILIDAD SOCIAL EMPRESARIAL Y EL PAPEL DEL ESTADO PARAGUAYO EN LA EXTRACCIÓN DE HIDROCARBUROS
}

\author{
THE CHACO BOREAL IN THE CURRENT TRANSNATIONAL \\ CONTEXT: CORPORATE SOCIAL RESPONSABILITY AND THE \\ ROLE OF THE PARAGUAYAN STATE IN THE EXTRACTION OF \\ HYDROCARBON
}

Áurea Vecino Caballero'

\begin{abstract}
RESUMEN: El presente trabajo tiene como objeto central determinar las actuaciones del Estado paraguayo y las empresas transnacionales que explican la situación actual que vive el Chaco paraguayo en su histórico conflicto por la tierra; a partir de la incorporación de las nuevas industrias extractivas de hidrocarburosdesde el anuncio de la compañía President Energy sobre su interés en la prospección y extracción de hidrocarburos en el Chaco Boreal a finales de 2014. Anuncio que desencadenó una serie de medidas por parte del Gobierno paraguayo, entonces liderado por el colorado Horacio Cartes, que acabó por modificar la matriz energética del país y las prioridades del Estado respecto a las políticas de uso de la tierra, algo que afecta directamente a las comunidades indígenas y el medio ambiente, en favor de los intereses empresariales. Y todo dentro del marco que establecen los procesos de desregulación en las relaciones comerciales internacionales, derivados de la globalización, el llamado softlaw, y sus correlativos sistemas de autocontrol, utilizando para el análisis de estas actividades extractivas la denominada Responsabilidad Social Empresarial.
\end{abstract}

PALABRAS-CLAVE: Chaco paraguayo. Extractivismo. Empresas transnacionales. Responsabilidad Social Empresarial. Hidrocarburos.

ABSTRACT: This work has the goal of explaining the actions of the Paraguayan State and transnational companies regarding the actual condition of the Paraguayan Chaco and its historical land conflicts. The study takes into account the events that took place since arrival of the new extractive industries and the announcement of the company President Energy, at the end of 2014, about its intentions to do prospections and to extract hydrocarbons in the Chaco Boreal. The announcement gave birth to a series of policies by part of the Paraguayan government, headed by the colorado Horacio

1 Máster en América Latina y Unión Europea: una cooperación estratégica - Universidad de Alcalá de Henares. E-mail: aurea.vecino@gmail.com. 
Cartes. Those policies modified both the energetic core of the country and State priorities regarding the use of the land, what affected both the Native Peoples and the environment, all in favor of entrepreneurial interest. All the facts are analyzed in the context of processes of deregulation in international commercial relations that derived from the globalization process, and under the scope of what has been labeled as "soft law" (through its respective systems of self-control) and Corporate Social Responsibility.

KEYWORDS: Paraguayan Chaco. Extractivism. Transnational companies. Corporate Social Responsability. hydrocarbon.

\section{INTRODUCCIÓN}

El conflicto por la tierra en Paraguay surge de un proceso constante de acumulación de la tierra caracterizado, asimismo, por el despojo de la misma a sus verdaderos propietarios: las comunidades indígenas del Chaco. A esta "acumulación por despojo" (HARVEY, 2004) debe añadirse el motivo por el que se produce: la implantación de empresarios extranjeros y empresas extractivas de diversa índole desde el siglo XIX y que hoy suman un nuevo rublo: los hidrocarburos ${ }^{2}$. Aunque el conflicto por la tierra no es el objeto principal de este trabajo sí se ve altamente influenciado por las actividades y relaciones que desarrollan los dos agentes objeto de estudio: el Estado y las empresas transnacionales de hidrocarburos.

Debido a la amplia repercusión sobre el Chaco de las acciones de estos dos agentes conviene aclarar que este conflicto por la tierra tiene su raíz profunda unida a causas históricas como la Guerra de la Triple Alianza (1865-1870) con la que se produce el fin de la independencia económica de Paraguay o la Guerra del Chaco (1932-1935) por el control de las tierras ricas en petróleo. Entender el funcionamiento de las empresas hoy instaladas en el Chaco Boreal pasa por conocer la manera en la que el Chaco pasó de ser un desierto al objetivo empresarial. El desarrollo de la industria extractivista, las empresas transnacionales y la manera en la que se obtiene la propiedad de la tierra hoy tiene su origen en los movimientos políticos y empresariales que se llevaron a cabo tras ambas guerras. En pleno siglo XIX el Gobierno paraguayo facilitó la extranjerización del Chaco otorgando beneficios fiscales a quienes se instalaran para producir en esta zona. Como explica Dalla-Corte:

Impulsado este interés por los grupos económicos, una de las consecuencias más evidentes fue la entrega de tierra fiscal a propietarios particulares que en pocos años asumirían el control de las riquezas de la región, entre ellas la explotación de los quebrachales y la extracción de tanino (DALLA-CORTE, 2007, p. 486).

Conviene señalar que, junto a las causas históricas de este conflicto por la tierra, la actualidad del Chaco paraguayo está marcada por la incursión de nuevos sistemas

2 La empresa petrolífera President Energy manifestó públicamente en octubre de 2014 su interés por instalarse en el Chaco paraguayo para realizar labores de prospección y extracción de petróleo y gas, a pesar de que anteriormente al anuncio la empresa ya había traspasado la frontera desde Argentina, donde tiene una de sus bases. 
de extracción de hidrocarburos. Por tanto, también se dan implicaciones del contexto global fruto de la dependencia del petróleo en la matriz energética mundial y de las características de las actividades extractivas en sí. Schuld y Acosta determinan que:

La actividad de exportación de bienes primarios consolida y profundiza la concentración y centralización del ingreso y de la riqueza en pocas manos, así como la del poder político. Las grandes beneficiarias son las empresas transnacionales, que conducen a una mayor "desnacionalización" de la economía, en parte por el volumen de financiamiento necesario, en parte por la falta de empresariado nacional consolidado y también por la poca voluntad gubernamental para formar alianzas estratégicas (SCHULD; ACOSTA, 2006, p.79).

\section{DESREGULACIÓN DE LAS ACTIVIDADES PRODUCTIVAS Y COMERCIALES Y LA RESPONSABILIDAD SOCIAL}

Retomando las primeras actividades empresariales desarrolladas en el Chaco, esas empresas del s. XIX representan los orígenes históricos ${ }^{3}$ de las compañías transnacionales actuales por el que las fronteras se diluyen y el Estado relaja su intervención. Conviene ahora explicar por qué surge este nuevo modelo de empresa, en qué contexto y qué consecuencias supone hoy para el Chaco. El modelo de empresa transnacional surge en el desarrollo de la globalización (GARRIDO, 2017, p. 127) ${ }^{4}$ que es reflejo de la pérdida de soberanía propia del Estado-nación, en este caso relativa a cuestiones comerciales.

En la globalización se dan dos procesos paralelos respecto a la producción y comercio, a nivel económico se da lo que en palabras de Robert Gilpin recogidas por la profesora Garrido:

hay un mercado en vías de unificación a través de la elaboración de una zona planetaria de producción y de intercambios; firmas mundiales que gestionan este sistema de producción y comercialización; y una lógica financiera de rentabilidad que ha de ser lo más ágil posible y ha de explicar en última instancia el movimiento de esos flujos (GARRIDO, 2017, p. 28).

3 De todos los empresarios del momento quien más influencia y poder tuvo en Paraguay en el siglo XIX fue el español Carlos Casado del Alisal. Afincado en Argentina donde hizo un imperio, cruzó la frontera para levantar en el Chaco paraguayo un puerto y líneas de ferrocarril que le permitieran exportar la madera y otros bienes comunes que estaba explotando. Sus actividades las financió con Banco Casado, que luego sería la sede del Banco de Londres en la zona, vinculando así los intereses económicos y geoestratégicos de las grandes potencias del momento con la fragilidad de las instituciones paraguayas y la corrupción del Estado (DALLA-CORTE, 2007; 2012).

4 Este fenómeno presenta múltiples definiciones y periodizaciones y, por tanto, rasgos definitorios que difieren según los autores pero el más extendido y aceptado, a nuestro entender, es el que le sitúa en la década de los años ochenta del siglo XX, "la globalización, definida estrictamente, comenzó o se intensificó tras la Segunda Guerra Mundial y que se consolidó entre las décadas de 1980 y 1990 (Castells, 2000; Conversi, 2010), coincidiendo con la aparición de las TIC, la intensificación de las comunicaciones físicas y la expansión mundial de los mercados de bienes y, sobre todo, de capitales, favorecidos por un nuevo clima político" (MARTIN-CABELLO, 2013, p. 11). Esta postura sostiene que, a pesar de existir una influencia estructural del pasado, como ocurre con las actividades de las empresas e infraestructuras creadas por Carlos Casado del Alisal en el Chaco a finales de 1800; tiene unas características propias a nivel comercial, jurídico, social, cultural, ideológico...que influyen de manera global en todos los campos y en todo el mundo y están vinculadas a la capacidad de agencia de determinados entes que las han impulsado, como son el Estado y las empresas transnacionales. 
Por otro lado a nivel jurídico, conviene señalar un proceso de desregulación jurídica que se traduce en el retroceso del Derecho público que se destina a protección social, laboral, etc., en beneficio de otras de Derecho privado y de autorregulación de grandes empresas dejando de lado la legislación intervencionista en favor de una abstencionista, permisiva con las normas que hacen los agentes económicos y sociales conforme a las reglas del libre mercado (GARRIDO, 2017). Esta desregulación, o falta de norma positiva se suple, muchas veces, por directrices y alcanza la categoría de fuente del Derecho extranacional, bajo el nombre de softlaw, que se podría describir "como nuevos arreglos de gobernanza, que si bien tienen carácter normativo, carecen de rasgos tales como obligatoriedad, uniformidad, justiciabilidad, sanciones o autoridades que los hagan cumplir" (ÁNGEL CABO, 2008, p. 9).

Propone y recomienda, no obliga, y se presupone buena fe. Las características mismas del softlaw puede generar problemas en un ambiente de desregulación estatal cuando se de una controversia con una empresa ${ }^{5}$. En este sentido, y para prevenirlos, surgen una serie de instrumentos de autocontrol, con carácter moral y voluntario, que se agrupan en la llamada Responsabilidad Social Empresarial (RSE) ${ }^{6}$. La manera en las que las recomendaciones del softlaw en la esfera internacional son transmitidas o se hacen saber puede tomar muy diversas formas como declaraciones de una conferencia intergubernamental o directrices de organismos de organizaciones internacionales. A tales efectos, se observa que el empleo del softlaw es mayor en los ámbitos de los derechos humanos y del medioambiente, precisamente los dos sujetos pasivos de las consecuencias del extractivismo y el conflicto por la tierra en el Chaco.

En este sentido, es fundamental el compromiso moral que supone asumir una actitud de RSE. Pero no es única. El reparto de la responsabilidad de las consecuencias de la actividad empresarial está vinculado con la responsabilidad social ejercida por el Estado donde se produce, se extrae, se comercia...etc. En un contexto como el que supone poseer yacimientos de petróleo, con el peso en el mercado mundial que conlleva, puede incentivar que la responsabilidad del Estado disminuya. El interés del Estado, como parte interesada, puede tender más hacia el aprovechamiento de los beneficios en términos económicos que en términos sociales ${ }^{7}$. Hay que añadir la reactivación de la lexmercatoria ${ }^{8}$. La relevancia de ello para este trabajo es el reconocimiento de una

$5 \quad$ Ahí es donde interviene la mediación o las normas de arbitraje internacional como las del Instituto Internacional para la Unificación del Derecho Privado (UNDROIT) o la Comisión de Naciones Unidas para el Derecho Mercantil Internacional (UNCITRAL).

6 Para definirla RSE, aparece el mismo problema que anteriormente, son diversos los autores y las consideraciones pero "parece existir acuerdo en que la RSE implica deberes y obligaciones, pero deberes y obligaciones que no surgen propiamente de requerimientos legales, sino del "compromiso", "respaldo" y "apoyo" de las empresas. En últimas, estas definiciones enfatizan el carácter voluntario y de autorregulación de las empresas que se comprometen con la RSE" (ANGEL CABO, 2008, p. 9). Asimismo, conviene señalar que en la actualidad, "la responsabilidad social empresarial va más allá de la pura filantropía del pasado y se ha convertido en una práctica donde las empresas aceptan promover mejores condiciones para la comunidad que los rodea como por ejemplo, mejores prácticas laborales, compromiso con la comunidad local, compromiso con el medio ambiente y contribución al desarrollo sostenible" (ANGUITA OYARZUN, 2017, p. 217).

7 Así, es común que, en países donde existen bienes comunes claves donde las instituciones no son fuertes, se tienda a una desregulación en favor empresarial como modo de atraer Inversión Extranjera Directa (IED), para justificarla afirmando que la inyección de dinero que supone en términos macroeconómicos se traduce en mejoras sociales o de infraestructuras (GUDYNAS, 2012).

8 Autores sitúan su nacimiento en Roma pero coge su nombre de la Edad Media. "Se trata de Derecho 
línea de actuación en el comercio internacional que facilita la implantación de empresas transnacionales por todo el mundo y cuyo régimen normativo, como acaba de exponerse, a veces no está en manos del Estado donde la empresa extranjera se ha instalado. Por el contrario, los conflictos que pudieran surgir, o bien se rigen por normas como los Principios UNIDROIT o por otras directrices de los organismos de softlaw. A pesar de que el análisis posterior se realiza respecto a un contrato de concesión que establece el Estado paraguayo bajo su normativa nacional, existen problemas que las empresas de extracción de hidrocarburos instaladas en el Chaco generan y, sin embargo, se benefician del sistema asumido de comercio internacional de bienes comunes, caracterizado por la exportación de los mismos sin haber generado un valor añadido significativo (GUDYNAS, 2013, p. 80).

\section{EL ESTADO PARAGUAYO Y LA RESPONSABILIDAD SOCIAL EMPRESARIAL}

El papel del Estado paraguayo en la industria extractiva es fundamental, Paraguay es el tercer país en el mundo en producción de soja para la exportación. Hoy suma un nuevo elemento: los hidrocarburos. En los primeros años del siglo XXI Sudamérica vivió un neo-extractivismo que se caracterizó por un Estado mucho más presente y que, normalmente, se efectuó desde gobiernos de izquierda. En este sentido, Gudynas (2012, p. 135) entiende que "el Estado contemporáneo libera y apoya dinámicas propias de una economía capitalista, permitiendo una intensa apropiación de la naturaleza; pero por otro lado, intenta regular e intervenir esos ámbitos mercantiles". Esta situación de cesión ante las normas del mercado pero control por parte del Estado que quiere beneficiarse de los rendimientos de la extracción del petróleo, se ajusta a la situación actual de Paraguay, según indica la normativa vigente, las concesiones otorgadas y otros aspectos que se pasan a analizar a continuación.

\subsection{MATRIZ ENERGÉTICA DE PARAGUAY Y SU REPERCUSIÓN SOBRE EL TERRENO CHAQUEÑO}

La política energética ${ }^{9}$ se ha convertido en un elemento clave, debido a la depen-

creado por comerciantes, para comerciantes y con procedimientos e instancias propias; si bien este Derecho aboga por las libertades civiles e individuales, la igualdad social y la nivelación económica" (GARRIDO, 2017, p.127). Aunque esa libertad de circulación internacional se perdió con el nacimiento de los Estados-nación, donde emerge un Derecho privado nacional que regula las actividades de los comerciantes. En el clima de desregulación generado a partir de la globalización, se retoma esta idea de reglas internacionales de comercio, para apoyar la caída de barreras y una regulación uniforme que puedan conocer y seguir todos los actores implicados en el comercio internacional. "El tema resulta de suma actualidad en Latinoamérica ante el cambio de la actitud tradicionalmente hostil mantenida contra el principio de la autonomía de la voluntad en vinculaciones internacionales" (MORENO, 2014, p.75). Ante ello, hay autores que la reconocen con carácter moderado, es decir, que no es un orden jurídico independiente de los nacionales; y con carácter avanzado, "aquella que viene dada por las prácticas de los comerciantes internacionales siendo un auténtico orden jurídico que compite con los Derechos nacionales, y puede regular un contrato autónomamente" (CALVO CARAVACA; CARRASCOSA GONZÁLEZ, 2006, p. 62).

9 Para entender el significado de política energética se ha recurrido a la definición que realiza Isidoro Tapia, analista del Instituto Espańol de Estudios Estratégicos, determina que "conviene distinguir claramente dos niveles en el análisis: la política energética que las autoridades responsables definen y persiguen en cada momento, y lo que podríamos denominar el modelo energético, el resultado de la interacción 
dencia mundial de los bienes energéticos para la producción y la influencia en las economías que ejercen las variaciones de su precio. Especialmente en el caso del petróleo y el gas. Es común que haya agentes interesados que permanezcan fuera de la toma de decisiones en estos asuntos, como es el caso de los pueblos indígenas del Chaco. Según Martínez Alier y Walter:

La expansión de las fronteras del petróleo y el gas se superpone con territorios indígenas, algunos de los cuales no habían sido previamente contactados, lo cual está promoviendo conflictos, enfermedades y el descontento entre estas comunidades (MARTÍNEZ ALIER; WALTER, 2015, p. 92).

Al amparo de la misma, Paraguay ha experimentado en apenas cuatro ańos un cambio tan significativo en su matriz energética que muestra los intereses prioritarios del Estado. En 2014 fue publicado un artículo sobre la matriz energética paraguaya por el profesor de la Facultad Politécnica de la Universidad Nacional del Este, Wilder Marcial Mereles Duarte, junto con la alumna María Angélica González Cantero, en el que afirmaban que "como conclusión del trabajo de investigación se puede destacar que en el sector energético del Paraguay la producción de energía primaria está compuesta exclusivamente por fuentes renovables de energía (hidroenergía y biomasa)" (MERELES DUARTE; GONZÁLEZ CANTERO, 2014, p. 56). Añadían, además, que "Paraguay no produce petróleo y la producción de gas natural es de carácter local y marginal y no representa, por el momento, aporte alguno a la matriz energética nacional". Sin embargo, hacían referencia a la existencia de la petrolera pública PETROPAR, señalando que el petróleo crudo que procesaba era importado de Argentina. En ese mismo momento, el Gobierno paraguayo ${ }^{10}$, entonces presidido por Horacio Cartes, se preparaba para un cambio en su matriz energética. Tras el anuncio de la existencia de yacimientos de crudo en el Chaco Boreal en octubre del mismo ańo por la petrolera President Energy, la política energética paraguaya introdujo en su matriz este nuevo rublo con la intención de explotar para exportar, como otros países productores.

Desde entonces el Viceministerio de Minas y Energía promociona y actualiza todos los datos relevantes para posibles inversores interesados en la prospección en el Chaco. Entre esos datos figura el anexo al Decreto n 6092/2016 sobre la Política Energética de la República del Paraguay ${ }^{11}$. Asimismo, inicia el texto declarando su visión estratégica que pasa por "atender a las necesidades de energía de la población en todos los sectores productivos", y añade "constituyéndose la energía en factor de crecimiento económico, desarrollo industrial y de progreso social, en el marco de la integración regional". En el análisis esto supone el cumplimiento de lo que anteriormente se señalaba respecto a

entre esa política y las decisiones de todos los agentes que participan en el sistema energético, incluidos no solo los gobiernos y reguladores, sino también empresas, consumidores, terceros países, etc." (IEEE/ TAPIA RAMIREZ, 2017).

10 El Gobierno paraguayo ya sabía de los trabajos de exploración previos que la empresa de capital británico President Energy, con sede en Argentina, había llevado a cabo más allá del río Pilcomayo. Antes del anuncio, en Campo la Princesa, donde vive la comunidad indígena Nivaclé, "la petrolera inició actividades con cuatro topadoras y abrieron picadas durante cinco días, destruyeron la floresta, el manantial de agua, y hubo desaparición de animales" (ORTEGA, 2013, p. 68).

11 Entre sus metas destaca la introducción de unos objetivos propios para el sector de hidrocarburos "garantizar la provisión de hidrocarburos con responsabilidad social y ambiental, resguardar los derechos del consumidor final y promover la producción nacional de hidrocarburos" (Viceministerio de Minas y Energía, Política Energética en la República del Paraguay, 2016, p. 4). 
los nuevos extractivismos progresistas surgidos en Latinoamérica, a pesar de gobernar en Paraguay el Partido Colorado, de tendencia conservadora; cumple algunas de estas indicaciones hechas por Gudynas. Por lo que, esos gobiernos justificaban las tareas extractivas en el progreso social. Asimismo, el Gobierno señala el modo en el que lo va a hacer: a través de los organismos de integración regional, es decir, a través de planes como IIRSA-COSIPLAN, debido a las impresionantes necesidades de infraestructuras que supone la extracción de petróleo. Sin embargo, y a juzgar por el análisis de las concesiones y las nuevas concentraciones de tierra, falla la responsabilidad socio-ambiental por parte del Estado ${ }^{12}$. Se trata de una política energética enmarcada en un plan a largo plazo, cuyos objetivos se pretenden alcanzar antes de 2040. Y para ello, el plan de acción institucional ha perfilado las siguientes líneas estratégicas:

reglamentación y regulación de precio de combustibles regulados, reglamento sobre calidad de combustibles líquidos y gaseosos, estructura legal que favorezca el desarrollo de hidrocarburos nacionales, plan estratégico de PETROPAR para su gestión empresarial orientada a resultados (VICEMINISTERIO DE MINAS Y ENERGÍA, 2016, p. 23).

Se ajusta más a una estrategia puramente capitalista que a una visión de estándares deseables al amparo de la RSE en el marco de los Objetivos de Desarrollo Sostenible. El Gobierno paraguayo, actualmente presidido por otro colorado, Mario Abdo Benítez, es ejemplo de otros gobiernos que, curiosamente, tienen corte progresista en los que también se reactiva y potencia el peso de la petrolera nacional, es el caso de Brasil y de Argentina.

12 Esta construcción de infraestructuras delegada que empezó en 2018, recoge el testigo de la del siglo XIX, donde a falta de entes regionales eran las propias empresas las que construían las carreteras, puertos, líneas de ferrocarril, como hacía Carlos Casado del Alisal (DALLA-CORTE, 2007, p. 488). 
Figura 1 - Catastro de hidrocarburos

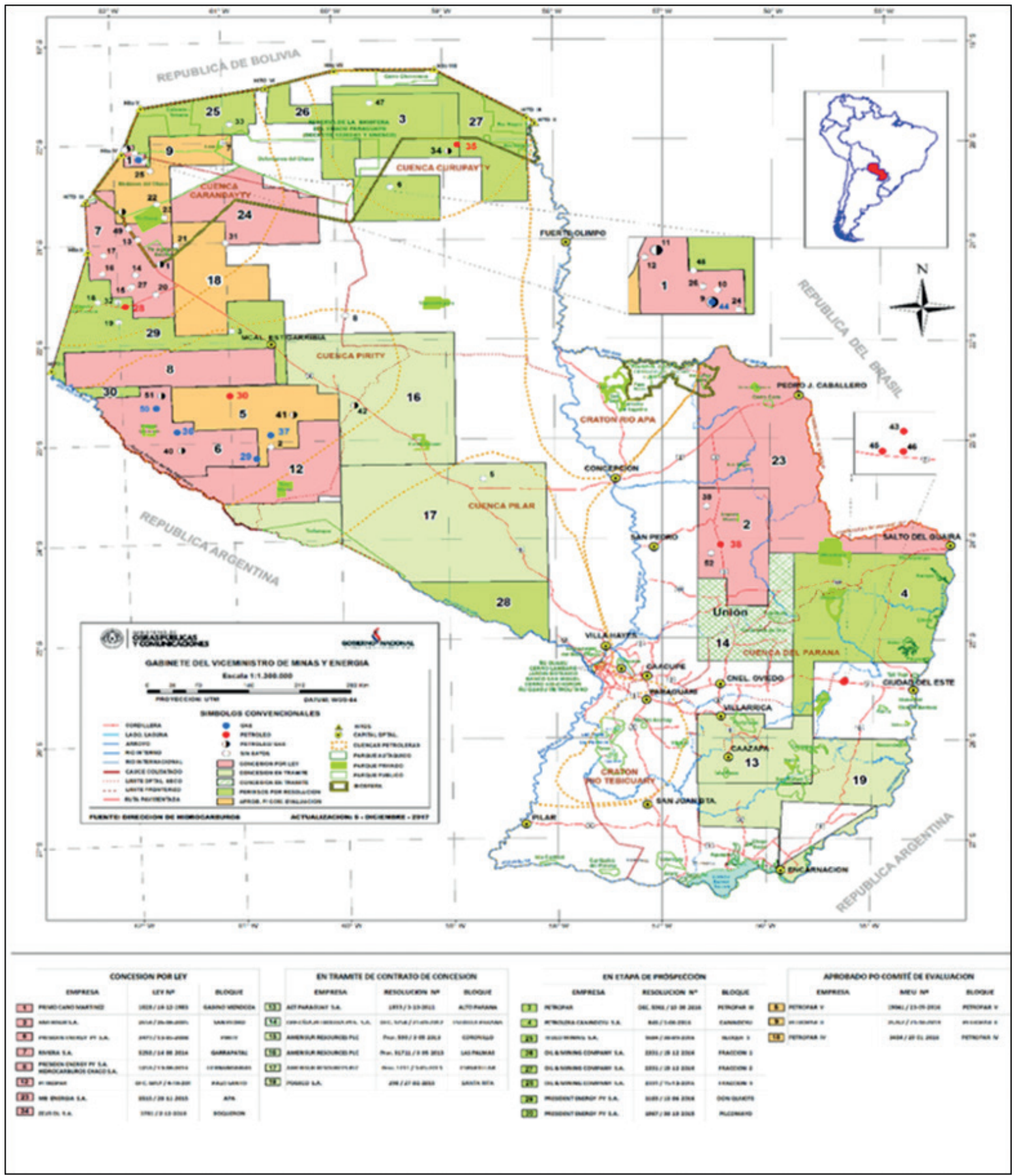

FUENTE: Viceministerio de Minas y Energía del Paraguay (2018).

Las líneas amarillas discontinuas del gráfico se corresponden con las cuencas petrolíferas y, a su vez, con las zonas ocupadas por las comunidades indígenas como la Guaraní Nandeva del Departamento de Boquerón, cuyo caso de abuso ya ha sido denunciado. En el Chaco, compartiendo territorio con las industrias extractivas hay 
173 aldeas, según los datos del Censo Nacional de Población y Viviendas para Pueblos Indígenas 2012 de la Dirección General de Estadística, Encuestas y Censo ${ }^{13}$.

A la vista de la distribución de pozos y comunidades conviene reflexionar entonces, al hilo de la desregulación y la asunción de RSE, sobre el concepto de buen gobierno, según explica Stoker:

hace referencia a un conjunto de instituciones y agentes procedentes del gobierno, pero también de fuera de él, reconoce la pérdida de nitidez de los límites y las responsabilidades tocante a hacer frente a los problemas sociales y económicos, identifica la dependencia de poder que existe en las relaciones entre las instituciones que intervienen en la acción colectiva, se aplica a redes autónomas de agentes que se rigen a sí mismas reconoce la capacidad de conseguir que se hagan las cosas, que no se basa en el poder del gobierno para mandar o emplear su autoridad. Considera que el gobierno puede emplear técnicas e instrumentos nuevos para dirigir y guiar (STOKER, 1998, p. 3).

De las áreas silvestres protegidas de Paraguay conviene señalar la Reserva Natural del Norte del país, comprende los territorios de los departamentos de Boquerón y Alto Paraguay y está afectada por las concesiones de terreno para exploración y prospección petrolífera dentro de la Cuenca Carandaity. Esta reserva natural está reconocida por Decreto del Estado paraguayo y cuenta con el reconocimiento de la Unesco. Es también llamativa la Reserva para Parque Nacional Tinfunque cuya localización coincide con la Cuenca petrolífera Pirity, la mayor área del Chaco entregada en forma de concesiones a industrias transnacionales para la explotación de petróleo. Esa misma zona es el área de familias indígenas.

\subsection{NORMATIVA PARAGUAYA Y JURISPRUDENCIA}

La relación entre Estado y empresas transnacionales queda reflejada a partir del análisis del modelo de concesiones. En Paraguay se puede observar una aparente falta de participación activa de las comunidades indígenas en contra de lo establecido por su Carta Magna, "Se garantiza a los pueblos indígenas el derecho a participar en la vida económica, social, política y cultural del país, de acuerdo con sus usos consuetudinarios, esta Constitución y las Leyes nacionales" (Constitución del Paraguay, 1992, art. 65). Lo mismo ocurre con el medio ambiente ${ }^{14}$.

13 La situación legal de estas comunidades es variada respecto a la posesión de los títulos de sus tierras. De todas, "357 comunidades censadas cuentan con tierra propia (72,4\%), de las cuales 343 poseen el título a nombre de la comunidad". Aunque son más las que poseen personalidad jurídica, 425 . Sin embargo aún hay 68 comunidades que no cuentan con el reconocimiento de sujetos de Derecho y, por lo tanto, es para estas comunidades mucho más complicado acceder a formalizar la titularidad de sus territorios. Respecto a ello, en la región Occidental, "totalizan 687.064 hectáreas de tierra titulada a nombre de las comunidades, de las cuales 489.875 hectáreas de monte (71\%)" (Censo Población Indígena 2012). Esto significa que aún es necesario que las comunidades indígenas sean reconocidas como sujetos de Derecho para poder acceder al sistema que les habilita para ejércelo.

14 Los contratos establecidos por el Gobierno han variado mejorando la protección de estos yacimientos a favor del Estado paraguayo, pero a pesar de que en el modelo de concesión más reciente se haga referencia a la necesidad de que la concesionaria aporte un informe de impacto medioambiental (Ley 779/95 de Hidrocarburos, 1995, art. 76 De protección al medio ambiente) ajustándose a la normativa internacional, existen denuncias sobre la falta de cumplimiento legal. Asociaciones civiles, como la Coordinadora de Derechos Humanos del Paraguay (CODEHUPY) o Centro por la Justicia y el Derecho Internacional (CEJIL), que ejercen como representantes legales de las comunidades indígenas afectadas, 
En el nuevo modelo de concesión se aprecia un ligero aumento del proteccionismo del Estado hacia estos yacimientos respecto a las empresas que operan en ellos, aunque no llega a nacionalizar la producción. Existe una cláusula en la que se establece que la concesionaria adquiere el compromiso de formar a funcionarios paraguayos. Esto sí representaría la aplicación de principios de RSE por parte del Estado, en el ámbito del desarrollo social, con la aplicación de estrategias nacionales positivas con incentivos empresariales (ELÓSEGUI ITXASO, 2010), pero no se hace mención a las plusvalías hacia los indígenas.

El cambio de los intereses del Estado se aprecia en la evolución de los contratos, como el suscrito a favor de la industria extractiva Paraguay Gan \& Energy S.A. el 14 de diciembre de $2010^{15}$ y el modelo tipo ${ }^{16}$ propuesto a día de hoy. En este último se le otorga gran importancia a las garantías que ofrece la concesionaria y a los beneficios destinados al Estado. Sin embargo, a pesar de reconocer que la concesionaria debe cumplir con la ley internacional respecto a la población indígena, no se exige que se aporte documento alguno que así lo demuestre. Tampoco existe la figura del representante de estas comunidades, cuya participación y consentimiento sean reflejados a través de su firma. Por ello, es fácil que este término no llegue a producirse pues el control es mínimo en este aspecto, como denuncian asociaciones civiles que trabajan en la zona. De este modo se incumple con el Convenio 169 de la Organización Internacional del Trabajo (OIT), sobre el derecho de la consulta previa.

Asimismo, la pertenencia de la tierra se reconoce al Estado, en su cláusula tercera respecto al “Uso del Suelo, Constitución de Servidumbre y Expropiación”, respecto a lo cual afirma que todo el proceso se regirá bajo lo establecido en el Título XIII Capítulo XIII de la Ley $N^{\circ} 779 / 95$ “De Hidrocarburos". Si se acude a la ley, esta establece en su artículo 72 que "las concesiones de hidrocarburos, por referirse esencialmente a trabajos en el subsuelo, no afectarán los derechos del propietario del suelo". Sin embargo, queda sin determinar a quién se refiere como propietario.

En el artículo 73 determina que "cualquier daño que se causare al propietario u ocupante legal por causas derivadas del permiso o concesión, será indemnizado por el permisionario o concesionario". En el artículo 74 del mismo capítulo añade que:

si para la constitución de servidumbre de ocupación temporal sobre inmuebles de propiedad privada, no se llegare a acuerdos entre el propietario del suelo y el concesionario, el Ministerio de Obras Públicas y Comunicaciones, a petición de éste último, tendrá la facultad de constituir administrativamente la servidumbre de ocupación solicitada, precisando su plazo, objeto, alcance y determinando la indemnización que debe abonar el concesionario al propietario (Ley 779/95 de Hidrocarburos, art. 74).

denuncian falta de cumplimiento de estos puntos y transparencia en el proceso (ROJAS VILLAGRA, 2014, p.7), y por ello han iniciado acciones legales para resarcir los daños causados a las comunidades, como es el caso del pueblo Guaraní Ñandeva.

15 Ley N4222. Concesión Empresa Paraguay Gan \& Energy S.A.

16 Contrato de Concesión de Hidrocarburos. 


\section{Y, por último, este capítulo termina con el artículo 75 en el que establece que:}

el concesionario podrá gestionar, por intermedio del Poder Ejecutivo ante el Congreso Nacional, la sanción de la Ley pertinente, para expropiar inmuebles de propiedad de particulares, en la medida necesaria para el completo desenvolvimiento de sus actividades y el pleno aprovechamiento de sus derechos (Ley 779/95 de Hidrocarburos, art.75).

Y aclara que, en este caso, sería concedida una indemnización al propietario en función de lo que establece el artículo 109 de la Constitución Nacional del Paraguay. Es decir, que el contrato, sólo se suscribe entre el Estado y la empresa concesionaria. Que la figura de propietario queda difusa. Si en un principio el articulado la usa para referirse a los ocupantes de los terrenos concedidos a la industria, en la práctica, ejerce de pleno derecho como propietario el Estado. Y no sólo eso. El Estado paraguayo facilita la actividad de la empresa extractiva hasta tal punto que, a pesar de solicitar justificación, se adelanta ante la posibilidad de que se ejecute una expropiación, facilitando tremendamente el camino a la concesionaria ${ }^{17}$.

Además de las características de la Ley n 779/95 de Hidrocarburos, existen más muestras de los intereses del Estado reflejados en normativa relativa a la tierra o beneficios fiscales. Según Gudynas:

El neo-extractivismo va más allá de la propiedad de los recursos, sean estatales o no, ya que termina reproduciendo la estructura y reglas de funcionamiento de los procesos productivos capitalistas volcados en la competitividad, la eficacia, la maximización de la renta y la externalización de los impactos sociales y ambientales (GUDYNAS, 2012, p.132).

Respecto a la propiedad de la tierra de las comunidades indígenas existe normativa nacional e internacional que la protege. En primer lugar, la Constitución del Paraguay recoge:

Los pueblos indígenas tienen derecho a la propiedad comunitaria de la tierra, en extensión y calidad suficientes para la conservación y el desarrollo de sus formas peculiares de vida. El Estado les proveerá gratuitamente de estas tierras, las cuales serán inembargables, indivisibles, intransferibles, imprescriptibles, no susceptibles de garantizar obligaciones contractuales ni de ser arrendadas; asimismo, estarán exentas de tributo. Se prohíbe la remoción o traslado de su hábitat sin el expreso consentimiento de los mismos" (Constitución del Paraguay, 1992, art. 64) ${ }^{18}$.

Conviene recordar que los títulos de tierras deben inscribirse en el Instituto

17 Aunque sin la denuncia oral de las comunidades indígenas no se puede demostrar un posible incumplimiento del convenio 169 de la OIT (a excepción de algunos casos documentados de denuncia), sí se puede afirmar que el Estado prima los intereses económicos y de inversión sobre el bienestar de una parte de su población, concretamente la más vulnerable, los indígenas de las zonas de extracción. El mismo contrato establece que el idioma oficial es el español y que así deberán hacerse las comunicaciones. Por lo que, si no había quedado clara la intención sutil de dejar fuera a las comunidades indígenas, con este detalle que excluye el guaraní, queda patente la exclusión de un agente olvidado, el poblador de estos territorios, el indígena.

18 A pesar de ello, la ley No 779/95 de Hidrocarburos reconoce la posibilidad de expropiación, al igual que el art. 128 de la Constitución, donde se justifica este hecho en el interés social sobre el particular. 
Nacional Indígena (INDI), pero, "en países como Paraguay, la tierra es uno de los bienes peor distribuidos y la estructura de su tenencia se traduce en uno de los más elevados índices de desigualdad social" (DOBRÉE, 2013, p.4). Esto ocurre porque históricamente ha sido el Estado el dueño de las mismas y las ha vendido y otorgado a través del Instituto de Desarrollo Rural de la Tierra (INDERT) y, en parte porque "la exigencia de que para poder ser titular del territorio de los pueblos indígenas se necesita tener personería jurídica, pero la misma no es una obligación ni mucho menos una costumbre según la idiosincrasia de los pueblos" (SOLEDAD DA COSTA, 2017, p. 79)19.

Asimismo, Paraguay está llevando a cabo una intensa labor de captación de inversiones extranjeras directas (IED), "la legislación sobre inversiones resulta muy favorable para la afluencia de capital productivo foráneo, destacando la Ley 117/91 y la Ley de Maquila. La presencia de IED se distribuye entre EEUU (29\%), Panamá (27\%), Brasil (23\%), Países Bajos (11\%) y Argentina (10\%) en datos de 2012 (OMAL, 2013). El régimen fiscal de Paraguay corresponde a un sistema de tributación territorial, lo cual significa que las empresas únicamente tributan por los ingresos obtenidos en el país, sin que se impute fiscalmente la renta obtenida en el exterior. Los dividendos distribuidos por sociedades residentes a sus socios igualmente residentes están exentos de tributación siempre que se cumplan determinados requisitos (ICEX, 2017). Esto fomenta la exportación de bienes comunes con poco valor añadido.

Es momento de analizar los casos paraguayos ante la Corte Interamericana de Derechos Humanos (Corte IDH) pues guardan relación con el uso que el Estado hace de los territorios de las comunidades indígenas, como hace en la actualidad a través de las concesiones para prospección petrolífera. “Las sentencias de 2005 (Yakye Axa), 2006 (Sawhoyamaxa) y 2010 (Xákmok Kásek) son fuentes del derecho para los pueblos indígenas y obligaciones para los Estados, más allá del caso" (SOLEDAD DA COSTA, 2017, p. 79). Según el informe Situación de los derechos a la tierra y al territorio de los pueblos indígenas del Paraguay, elaborado por la Coordinadora de Derechos Humanos del Paraguay:

Por tanto, cuando hablamos del marco jurídico, estamos hablando de la dimensión teórica que debe observar el Estado para organizar el poder público en función al cumplimiento de sus obligaciones, lo que importa, a su vez, la obligación de adoptar disposiciones de derecho interno (Coordinadora de Derechos Humanos del Paraguay, 2013, p. 9).

Actualmente los casos contenciosos en fase de Fondo, Reparación y Costas contra Paraguay son sólo 8. De ellos, sólo se corresponden con derechos de la tierra:

Comunidad Xákmok Kásek, el 24 de agosto de 2010 la Corte Interamericana de Derechos Humanos declaró responsable internacionalmente al Estado del Paraguay por la falta de garantía del derecho de propiedad comunitaria, las garantías

19 Asimismo, Paraguay ha ratificado tratados internacionales como el Convenio 169 de la OIT Sobre Pueblos Indígenas y Tribales en países independientes, que reconoce la relación especial que tienen los indígenas con sus territorios, incorporado a la legislación nacional a través de la Ley No 234/93 y la Declaración de Derechos de los Pueblos Indígenas. Pero siguen produciéndose reclamaciones sobre el territorio del Chaco por falta de coordinación de datos entre instituciones y el hecho de que la tierra, a todos los efectos, sea del Estado hace que existan duplicidad de títulos de propiedad, títulos de dudosa validez y ausencia de los mismos (SOLEDAD DA COSTA, 2017). 
judiciales, la protección judicial, así como por la violación a los derechos a la vida, integridad personal, reconocimiento de la personalidad jurídica, los derechos del niño y por el incumplimiento del deber de no discriminar. Todo ello en perjuicio de los miembros de la Comunidad Indígena Xákmok Kásek (Corte IDH, 2010).

Comunidad Sawhoyamaxa, la Comisión alegó que el Estado no ha garantizado el derecho de propiedad ancestral de la Comunidad Sawhoyamaxa y sus miembros, ya que desde 1991 se encontraría en tramitación su solicitud de reivindicación territorial, sin que se haya resuelto satisfactoriamente (Corte IDH, 2006).

Comunidad Yakye Axa, del 17 de junio de 2005, los representantes de las víctimas reivindicaron que "el derecho de las comunidades indígenas a la propiedad colectiva de sus tierras se concreta", inter alia, "en la obligación del Estado de delimitar, demarcar y titular el territorio de las respectivas comunidades". La Corte, a su vez, reconoció la vinculación del "derecho a la propiedad comunitaria de los pueblos indígenas sobre sus territorios tradicionales y los recursos naturales ligados a su cultura" con el término “bienes” en el artículo 21 de la Convención (Corte IDH, 2005).

Con todo ello, y siguiendo los trabajos realizados por la doctora Nuria Belloso, es destacable la posibilidad de incorporar la figura del mediador que facilite acabar cuanto antes con la controversia generada, aunque para ello, es necesario que el Estado esté dispuesto a negociar. Se trata de una alternativa para agilizar los procesos y discernir los casos de necesidad de resolución inmediata. Conviene tener en cuenta que suelen ser denuncias que, aunque se efectúen en la actualidad, se basan en violaciones de derechos cometidas de forma continuada y, a veces, sistemática, cuyo origen se remonta años atrás. Conviene recuperar, entonces, el concepto de RSE que, según Garrido:

nos remite a demandas de la sociedad, a la respuesta que los núcleos empresariales realizan y a las implicaciones sociales que conllevan sus acciones. Esta es la razón por la que se refiere a temas como los derechos humanos, medioambiente, derechos laborales y ética empresarial (GARRIDO, 2017, p.132).

Paraguay acaba de recibir a la delegación de observadores internacionales cuya misión era certificar el cumplimiento de las sentencias emitidas por la Corte Interamericana de Derechos Humanos contra Paraguay. Un informe sin mucho detalle pero del que se desprende que aún no se han cumplido los fallos que la Corte emitió hace veinte años, sobre el cumplimiento de estas tres sentencias. El mismo informe de actividad 2017 de la Corte IDH reza:

Como complemento a la información recibida durante las visitas, en la audiencia el Estado fundamentalmente expresó compromisos concretos respecto al cumplimiento de las medidas de reparación y los representantes de las víctimas expresaron sus solicitudes y observaciones al Corte Interamericana de Derechos Humanos (CORTE IDH, 2018).

\section{LA RESPONSABILIDAD SOCIAL EMPRESARIAL Y LAS INDUSTRIAS EXTRACTIVAS DE HIDROCARBUROS EN EL CHACO}

Según los datos del Ministerio de Obras Públicas y Comunicaciones, a través de su Viceministerio de Minas y Energía, actualmente, disfrutan de una concesión para 
la ejecución de labores relacionadas con la extracción de crudo y gas las empresas ZEUS ÖL S.A (Ley 5761-16), MB Energía S.A. (Ley 5515-15), Rivera S.A. (Ley 525814), Hidrocarburos Chaco (Ley 5259-14), President Energy Paraguay S.A. (cedido por Decreto n. 4445/2015), Primo Cano Martínez (Ley 1028-83), Amerisur (Ley 2658-05) y por decreto otorgado a PETROPAR, cuya actividad cesó durante más de diez años y el gobierno paraguayo realizó un acuerdo con el francés en un intento por reactivarlo. Desde el primer análisis realizado a finales de 2017 hasta ahora se ha añadido una nueva concesión a favor de la empresa Compañía Petrolera Paraguaya S.A. (CPP S.A.) cuya concesión también se ha realizado con rango de ley (Ley 5960-18).

Lo interesante de estas concesiones es que, por la Ley de Hidrocarburos, todas ellas figuran con su domicilio social en Paraguay y cuentan con un representante con capacidad de firma que reside en el país.

Esto supone una dificultad añadida a la verdadera localización de la matriz de estas empresas y, por ende, a la atribución real de responsabilidades en caso de que fuera necesario y así como el control de los flujos de dinero y producto. A dónde van ambos y qué entidades se encargan de la fase de transformación, verdadera puesta en valor del crudo. Estas actividades de transformación son las que encarecen los productos derivados del petróleo y dónde se adquiere el mayor beneficio, algo de lo que los Estados como Paraguay, poseedores de pozos pequeńos en el contexto mundial, suelen quedarse al margen.

Esto genera lo que autores como Martínez Alier (2008) denominan "conflicto ecológico distributivo desigual", ya que los daños medioambientales los padece el país poseedor de estos yacimientos mientras que los beneficios de la actividad salen fuera de su mercado en su mayoría. Sin embargo, la problemática va más allá. No sólo existe un verdadero entramado de empresas de corte transnacional, también se dan otros asuntos como un oligopolio en todas estas actividades relacionadas con el petróleo y que tiene en el centro de todo al Gobierno paraguayo, que otorga y firma estas concesiones y lo hace con rango de ley.

El tipo de concesión no es el único problema. Desde su independencia el Estado, más concretamente, desde la dependencia económica con la deuda contraída con bancos extranjeros tras la Guerra del Paraguay, los sucesivos gobiernos paraguayos han normalizado la entrega de tierras fiscales con excesiva facilidad. Conviene recordar la necesidad de recuperarse tras la devastación que produjo la guerra y cómo el Estado asumió como suyas las tierras del Chaco Boreal y las vendió a bajo precio. "Se enajenaron 25.000.000 hectáreas de los 30.000.000 que tenía el país en un periodo muy corto y a precios muy bajos, procesos donde no participaba la población campesina indígena" (FERREIRA, 2017, p. 48). Desde ese momento estas prácticas han sido habituales según indica Dalla-Corte:

Impulsado este interés por los grupos económicos, una de las consecuencias más evidentes fue la entrega de tierra fiscal a propietarios particulares que en pocos años asumirían el control de las riquezas de la región, entre ellas la explotación de los quebrachales y la extracción de tanino (DALLA-CORTE, 2007, p.486).

Así comenzaba la explotación extractivista y, según muestran las concesiones actuales, así continúa. Este tipo de mecanismos no concuerdan con el nuevo orden de cosas en la esfera de los negocios y que parte de la RSE como "la respuesta que da un 
agente moral a los efectos de sus acciones al promover el desarrollo humano de las comunidades con que interactúan" (GARRIDO, 2017, p. 130). Pero estas actuaciones no son aisladas, Garrido añade a continuación que es "extensible al desarrollo de las prácticas responsables de las Administraciones Públicas y en las organizaciones públicas y privadas".

Ni entonces, ni ahora se ha tenido en cuenta la presencia y voz de los grupos indígenas originarios más allá de las medidas de coacción y violencia directa tomadas para adquirir sus territorios. En muchos casos, los países firmantes no incorporan los principios del Derecho Internacional en su normativa interna y a las interpretaciones judiciales que ejecutan sus cortes. Es el caso de Paraguay y su actuación histórica hasta hoy respecto a su población indígena (RODRÍGUEZ GARAVITO, 2016).

Rodríguez Garavito, abogado especialista en derechos humanos (DDHH) y activista director de la organización De justicia, sobre la justicia global, considera que el campo de los derechos humanos se encuentra en un momento en el que se mueve en muy distintas direcciones y cree que esto ocurre por cuatro cambios estructurales importantes: el ascenso de nuevas potencias mundiales (BRICS) que para él suponen que el Norte Global ya no es el único que implementa estándares sobre DDHH; el repertorio de actores, estrategias jurídicas y políticas se expandió considerablemente; las tecnología de la información y la extrema degradación ambiental, la cual considera una amenaza absoluta para los DDHH.

En la actualidad, el Chaco se ve afectado por las actividades de las empresas transnacionales extractivas. Se trata de empresas cuya deslocalización, incluso, a pesar de nacionalizar las filiales en los países receptores; no merma la subordinación de las filiales a las órdenes de la matriz (GARRIDO, 2017, p.128). Esto es importante a la hora de determinar sobre qué agente recae la responsabilidad de la acción empresarial. Hasta ahora las empresas se regían por "los valores" en la toma de sus decisiones pues sólo eran considerados sujetos de Derecho el Estado y los individuos. Así las cosas, era apreciable el vacío de responsabilidad que se dejaba a las empresas respecto de sus actuaciones.

Hoy,laempresa esresponsablejurídicamente, através delallamada Responsabilidad Social Empresarial (RSE). La profesora Garrido explica como las empresas transnacionales son "una modalidad empresarial que realiza actividades económicas en sectores muy distintos lo cual hace que sean dotadas de un amplio poder económico y político" (GARRIDO, 2017, p. 127). Esta puntualización ayuda a ilustrar la forma en la que se lleva a cabo la actividad transnacional de las petroleras en el Chaco.

ZEUS ÖL S.A. firma su concesión en calidad de representante Juan Enrique Rassmuss, la empresa MB Energía S.A. firma su concesión en calidad de presidente Marc Lionel Firmin quien también lo hace en la concesión de la empresa Rivera S.A. junto con Bernnard Francois Louis Verdu en calidad de vicepresidente de la compañía. Las concesiones de las compañías Hidrocarburos Chaco y President Energy Paraguay S.A. son firmadas en calidad de director-presidente por Ferdinand Wiens Boschman, quien en el caso de President figura como Fernando Wiens perteneciente a la compañía Pirity Hidrocarburos S.R.L, cuya concesión ha sido adquirida por la empresa Compañía Petrolera Paraguaya S.A. y cuyo representante legal es de nuevo Ferdinand Weins Boschman. El contrato de Amerisur lo firma Christopher Clark en calidad de 
representante y la empresa Primo Cano Martínez la firma él mismo pero se trata de un contrato de diciembre de 1983.

Dentro del marco de las relaciones de comercio internacional y la RSE se ha definido la presencia de partes o entes interesados en estos procesos en la Teoría de los Stakeholders, aquí se pueden identificar a algunos de ellos, personalmente.

Viendo estos datos no parece que el sistema de concesiones del Estado paraguayo responda a los estándares deseables de transparencia en actividades tan delicadas para el medio ambiente y su población autóctona como es la explotación de yacimientos de petróleo y gas en sus territorios ancestrales. Ante esta situación conviene destacar dos cosas. Primero, que "la promoción y defensa de los derechos humanos dentro del ámbito empresarial descansa en la autorregulación y códigos de conducta voluntarios" (GARRIDO, 2017, p. 127). Y segundo, el papel del Estado y su responsabilidad.

Esta inquietud parece confirmarse al comprobar que Marc Lionel Firmin es, además, la misma persona que negoció con el Gobierno paraguayo la reactivación de la actividad de PETROPAR como presidente de la entonces compañía CIFAL Paraguay ${ }^{20}$, empresa ruso-francesa. Y, a su vez, el responsable de la cámara de comercio francesa en Paraguay y presidente del Grupo Montecristo, además de haber ejercido de cónsul honorario de Francia en Paraguay.

Es el momento de señalar una cuestión acerca de la RSE. En la Unión Europea, es el Libro Verde el que recoge las directrices de los organismos de Gobernanza Mundial como OCDE, ONU y OIT (Paraguay ha ratificado todos). En este sentido Elósegui Itxaso dice:

Un tercer aspecto notorio destacable en los documentos de la UE es el interés por las cuestiones internacionales, enfocadas desde la perspectiva de Cooperación al desarrollo en los países terceros en los que trabajan las empresas europeas. Los Estados miembros de la UE, y la UE como institución, se sienten obligados éticamente y en justicia en relación con el desarrollo de los países que han sido antiguas colonias (ELÓSEGUI ITXASO, 2010, p. 13).

Atendiendo al análisis de María Elósegui Itxaso sobre la Responsabilidad Social Corporativa (RSC), predecesora de la RSE, en la UE; cabe destacar que las empresas ubicadas en el Chaco pertenecen a capitales europeos y americanos en su mayoría, aunque se da también presencia nacional y latinoamericana. Así las cosas, las concesiones para la prospección y explotación de hidrocarburos en el Chaco no respetan lo que en sus países de origen les son exigibles a estas empresas. Un reclamo que nace, en principio, de las demandas sociales basadas en el respeto a unos estándares mínimos de derechos humanos y ambientales. Por lo tanto, los representantes en la firma de estos contratos de concesión, de origen europeo, también están pasando por alto estas directrices de ética empresarial.

A ello se une una forma de actuar del Estado paraguayo que no hace más que favorecer los intereses de las empresas de capital extranjero en el país y fomentar el enriquecimiento de unos pocos, puesto que las limitaciones en la extensión máxima de terreno por concesión, son toreadas a través de la firma de los convenios

20 Puede obtenerse más información en el Viceministerio de Minas y Energía del Paraguay, "Reactivación de la compañía petrolera paraguaya PETROPAR". 
por medio de representantes de terceros para, posteriormente, reunir las hectáreas concedidas a través de la negociación o compra por parte de compañías más grandes como President Energy a otras más pequeñas como se ha indicado. Un sistema de concentración de la tierra que recuerda al utilizado por Carlos Casado del Alisal en el siglo XIX, quien se sirvió de una decena de prestanombres para hacerse con las concesiones del Chaco. Una extensión que superaba el límite máximo legal. “El empresario transnacional no desaparece, sino que reaparece bajo otros modelos de asociación, tales como la migración a contratos por servicios en el sector petrolero o "joint-ventures" para la comercialización (tal como sucede, por ejemplo, en Bolivia) (GUDYNAS, 2012, p. 132).

Alejandro Teitelbaum recoge la definición de empresa transnacional que la Corte Suprema Argentina realizó en 1973, una definición muy reveladora para lo que se está exponiendo. La Corte estableció que:

\begin{abstract}
cuando el status jurídico de la filial hace aparecer a ésta como una entidad independiente es preciso "levantar el velo" de la ficción jurídica y establecer la realidad económica, de modo que la sociedad matriz no pueda eludir sus responsabilidades. Es decir, que la sociedad transnacional, aunque tenga la apariencia jurídica de una pluralidad de sociedades, constituye, en lo esencial, una unidad económica con un centro único con poder de decisión (OMAL/TEITELBAUM, 2017).
\end{abstract}

Ante esta abrumadora realidad, parece impensable hablar de implantación de medidas que intenten fomentar la justicia y un vínculo ético con la sociedad y el entorno en que se desenvuelven estas empresas como supone la asunción de la RSE.

Enmarcada dentro de las políticas sociales de la Unión Europea y como uno de los vehículos para ejercer una actividad empresarial más sostenible, entre otras cosas, supone la aceptación por parte de las empresas de un compromiso con el desarrollo local, actividades al amparo de los derechos humanos (de aplicación en este caso de los Derechos de los Pueblos Indígenas) y la contratación pública socialmente responsable (Comisión Europea sobre Responsabilidad social de las empresas). Conviene destacar que, igual que se puede hacer una valoración negativa acerca del sistema de concesiones paraguayo también se puede hacer la lectura de responsabilidad a estas empresas cuyo capital proviene principalmente de Francia, Rusia, Gran Bretaña y EEUU. Todos ellos, países que han ratificado la Declaración Universal de Derechos Humanos y forman parte de los que han firmado los Objetivos de Desarrollo del Milenio.

El tan ansiado desarrollo sostenible con sus políticas de respeto al medio ambiente queda muy lejos mirando de cerca la actividad de estas industrias en Paraguay. Ya que para que de verdad haya un compromiso y, se asuma esta RSE, debe existir una voluntad. Las instituciones públicas no pueden permanecer al margen de estos fenómenos, incorporando un marco que sirva para promover y facilitar la RSE a la hora de elaborar medidas concretas, aplicarlas o verificarlas (BAZ TEJEDOR, 2007, p. 328). Asimismo, destaca que este concepto está estrechamente vinculado a la idea de Desarrollo Sostenible, una vez más, supone un compromiso y una voluntad de respetarlo y, de momento, no parece que lo haya en Paraguay. 


\subsection{LA RSE FRENTE AL EXTRACTIVISMO Y LAS COMUNIDADES INDÍGENAS}

Según Dávalos, existen una serie de falacias en torno al discurso extractivista. Así, el autor recoge los pensamientos de varios autores y explica que:

El fenómeno del extractivismo significa mucho más que la simple extracción de recursos naturales, implica dinámicas territoriales, valorización mercantil de recursos intangibles, derechos de propiedad sobre recursos territoriales en mercados altamente integrados sobre todo mercados financieros, dinámicas de política demográfica y de control poblacional como por ejemplo las Transferencias Monetarias Condicionadas, relaciones geopolíticas que establecen nuevas formas de integración regional tanto a nivel político cuanto a nivel de infraestructura, que procesan nuevas formas de hegemonía mundial, procesos de desposesión territorial y judicialización social, control territorial por vías paramilitares (DÁVALOS, 2013, p. 2).

A lo largo de todo este capítulo se está presentando la situación en el Chaco desde una perspectiva de RSE, como "el ideal", enfrentada a los agentes: Estado y empresas. Pero también es pertinente valorar algunas cuestiones frente al extractivismo y su efectividad frente a las comunidades indígenas. La aplicación de la RSE en lo relacionado con el medio ambiente supondría la práctica de una serie de medidas que, en palabras de Atehortúa Hurtado:

a través de la promoción interna y externa de una cultura de prevención de la contaminación y uso racional de los recursos naturales. Putterman se refiere específicamente al uso controlado de materiales, energía, agua, biodiversidad y a la reducción de las emisiones, efluentes y desperdicios (ATEHORTÚA HURTADO, 2008, p. 131).

Aquí surge el primer problema, pues extractivismo y desarrollo sostenible son dos conceptos enfrentados y, por tanto, será muy improbable alcanzar estándares de RSE en el ejercicio de las tareas extractivas.

En segundo lugar surge otro dilema respecto a la aplicación de RSE y las comunidades indígenas que viven el Chaco y de qué manera la aplicación de RSE puede influirles, como matiza Elósegui Itxaso:

Las cuestiones de acción organizacional van tomando importancia en los dos lados del Atlántico como "ética de las organizaciones" o "ética empresarial", pero Estados Unidos va por delante en el debate y en la construcción de teorías elaboradas como la de los stakeholders. En Europa se está prácticamente empezando. Ya hemos visto que el Libro Verde entra de lleno y que apoya en esa teoría su estrategia de RSC (ELÓSEGUI ITXASO, 2010, p. 15).

Teniendo esto en cuenta conviene definir el enfoque del término stakeholders, "estima que los intereses de una empresa comprenden a los accionistas y al grupo afectado por sus decisiones y acciones" (GARRIDO, 2017, p. 146). En este grupo de "afectados por sus acciones" deberían figurar el medioambiente y las familias indígenas. Garrido explica que:

Los grupos de interés son los grupos sin los cuales la organización podría dejar de existir, o bien aquellos grupos sociales e individuos afectados por la existencia y acción de la empresa, que poseen un interés legítimo, directo o indirecto por 
su marcha, influyendo a la par en la consecución de los objetivos marcados y su supervivencia (GARRIDO, 2017, p. 147).

A la vista de estas consideraciones y tras lo expuesto sobre la falta de consulta previa a los pueblos indígenas para ocupar su territorio, la falta de documentación registrada acreditativa de impacto medioambiental, la carencia de presencia de representantes indígenas en los contratos de concesión y la falta de títulos de propiedad, en algunos casos, incluso con el incumplimiento de sentencias firmes de la Corte Interamericana de Derechos Humanos; surgen dos reflexiones.

La primera, que las comunidades indígenas y el medioambiente, a pesar de ser Sujetos de Derecho, no ejercen como afectados por las acciones de las empresas extractivas, a pesar de su interés legítimo y directo. La segunda, que esta falta de condición de afectado legitimado a ojos de Estado y empresa, los excluye del modelo de los stakeholders pues no tienen capacidad para influir en la consecución de los objetivos. Una posible solución pasaría por la puesta en práctica de un modelo de buen gobierno corporativo, más allá de los intereses de los accionistas y proveedores, se asume el bienestar de todos los interesados como un fin, y no como un medio para aumentar el beneficio privado de los accionistas, la empresa se identifica con el modelo pluralista o stakeholder (LIZCANO, 2006, p.25).

El modelo extractivista es el claro ejemplo de cómo la globalización deja fuera a los grupos más vulnerables, en este caso: las comunidades indígenas. Algunas de ellas presentan más resiliencia que otras, especialmente las más cercanas a áreas urbanas, pero no es el caso del Chaco.

En la cosmovisión indígena no caben ideas individualistas ni se concibe el beneficio económico como tal, ni el consumismo. Son grupos étnicos estrechamente vinculados a la tierra con la que mantienen un equilibrio vital recogido en el concepto sumakkawsay, por lo que difícilmente, aun cumpliendo con los estándares esperados de RSE por parte de las industrias instaladas en el Chaco; consigan aportar a la sociedad lo que esta espera de ellas. Muchos de estos grupos no necesitan carreteras, ni presas, lo que esperan es precisamente que no se modifique el territorio porque se destruye el ecosistema, ni que se les convierta en obreros, porque dejarían de ser cazadores.

Ante este problema, con difícil solución, el último informe realizado por el anterior Relator Especial ante el Consejo de Derechos Humanos de la ONU, James Anaya, realizado en el año 2013, centra su estudio en los Derechos de los Pueblos Indígenas ante la actuación de los Estados y las actividades de las industrias extractivas. Intenta plantear una especie de acomodo razonable para estas comunidades afectadas después de reunirse con representantes de pueblos indígenas, Estados y empresas interesadas. Reconoce la situación de vulnerabilidad en la que se encuentran los pueblos indígenas con el avance implacable de la extracción, especialmente bajo las condiciones que se dan en la actualidad. Hay casos en los que la extracción es incompatible con las aspiraciones de los pueblos indígenas y que, en muchos casos, a estos pueblos se les impide acceder a su tierra, algo fundamental para su supervivencia, en sus palabras:

On the other hand, there are certainly cases in which resource extraction is simply incompatible with indigenous people's own aspirations and priorities for development, or may impede their access to lands and natural resources critical to their physical well-being and the integrity of their cultures and livelihoods (UNSR/ANAYA, 2013). 
Asimismo, asegura que los avances tecnológicos han facilitado una disminución del impacto ambiental. En un informe previo realizado por Anaya siendo relator, explica las características del modelo de extracción predominante por el que el negocio se lleva a cabo por empresas extranjeras con el respaldo del Estado que les permite instalarse y donde las ganancias derivadas de la actividad suelen ir en su mayor medida a estas mismas empresas (UNSR/ANAYA, 2012). El agente al margen aquí son los pueblos indígenas que viven en esas tierras. Es importante recordar que la responsabilidad de garantizar efectivamente los derechos no recae sólo en los Estados, y, por tanto los intereses de las empresas deben ajustarse al menos en lo relativo al impacto de sus actividades sobre los derechos humanos (ASÚNSOLO MORALES, 2015, p. 99).

Para paliar esta falta de participación el Relator Especial propone la incorporación activa de estos pueblos a la actividad extractiva después de observar en muchos de ellos su interés por participar. Y ofrece, como alternativa al sistema de negocio actual, que sean empresas o alguna forma de colectividad integrada por indígenas las que lleven a cabo estas tareas extractivas. Sin embargo, Anaya se deja fuera estas cuestiones: supone un modelo en el que sólo participarían aquellos pueblos indígenas que hayan manifestado de forma expresa sus ganas de organizar esta industria (suponiendo el consentimiento de sus Estados) en sus tierras sin tener en cuenta quienes no quieren y se ven obligados. En segundo lugar, deja fuera de una posible solución a los pueblos indígenas en aislamiento voluntario. Un acomodo efectivo "requiere una visión positiva de las libertades, entre ellas del derecho a la propia identidad, forjada por variados elementos, como las convicciones filosóficas y religiosas, enfocando esa diversidad como una riqueza y no como un problema" (ELÓSEGUI ITXASO, 2014, p. 74).

\section{CONSIDERACIONES FINALES}

La globalización está impulsando un nuevo proceso de desregulación en pro de las normas neoliberales que se están aplicando en Paraguay. El Partido Colorado ha asumido el rol de algunos Gobiernos progresistas de la zona en el ámbito extractivista, para sacar rendimiento económico, especialmente de la industria de hidrocarburos. Fomenta políticas de atracción de inversión extranjera directa y facilita la obtención de tierras para la prospección y extracción de petróleo y gas en el Chaco. Ha modificado su Ley de Hidrocarburos pero sigue sin introducir a las comunidades indígenas en los contratos de concesión. Facilita la expropiación de terrenos y dificulta la obtención de títulos de propiedad a los pobladores originarios del Chaco. El Estado ejerce como dueńo de la tierra, la gestiona a través del INDERT y se beneficia con su venta. Reproduce, entonces, las prácticas establecidas tras la Guerra del Paraguay, con el inicio de extranjerización de la tierra a través de su venta a bajo precio, para la industria extractiva. Por lo que se aprecia falta de responsabilidad y compromiso social por parte del Estado. Asimismo, no ejerce grandes controles sobre los estudios de impacto ambiental presentados por las concesionarias, que tampoco son publicados. Por tanto, los cambios introducidos en la Ley 779/95 de Hidrocarburos están orientados a la participación del Estado en la gestión y control de los yacimientos al tiempo que incentiva la participación de empresas extranjeras. 
Las empresas transnacionales de capital europeo o norteamericano, principalmente, ven en Paraguay una oportunidad de negocio. Aprovechan la extracción para la exportación y casi no pagan impuestos por ello. Juegan a un doble papel pues en sus países de origen se les exige una ética en los negocios bajo la RSE; sin embargo, el Estado paraguayo no fomenta una actitud moral en los negocios ni un compromiso social y las corporaciones extranjeras se aprovechan de ello usando métodos, muchas veces, de hace dos siglos. Como el uso de "representantes" en la firma de contratos y la acumulación de tierras con la compra posterior de las concesiones hechas a empresas más pequeñas. De este modo, estas empresas transnacionales contribuyen al desequilibrio que genera la exportación de un bien común con bajo valor añadido, lo que genera un intercambio desigual por el que Paraguay sufre los llamados "fallos del mercado", de gran coste ecológico, mientras que el beneficio económico es repercutido en bajos costes de producción de las empresas y países que adquieren estos bienes.

Existen dificultades en la aplicación de la RSE en un marco extractivista donde residen comunidades indígenas. Por un lado, la definición de extractivismo no permite la asunción de moral respecto al medio ambiente. Es totalmente contrario a un desarrollo sostenible, por la mera razón de que ya no se estaría hablando de extractivismo. Por otro lado, no se puede ofrecer una ética o moral más allá de la ley, conforme a lo que la sociedad espera en sociedades multiculturales. Las expectativas de una comunidad indígena difieren mucho del resto de la sociedad. Esa cosmovisión reúne al hombre y la tierra en un mismo ser. Es, por tanto, impensable, que el ejercicio de la RSE en términos neoliberales pueda satisfacer las demandas de esa sociedad.

De aplicar la Teoría de los Stakeholders ni el medio ambiente ni las comunidades indígenas serían reconocidos como entes interesados con capacidad para influir en las decisiones de una empresa. Así pues, ambos, quedan fuera de la protección internacional moral que supone la RSE. Esto es fruto de un reparto de responsabilidades entre las empresas transnacionales y el propio Estado paraguayo que no vela por los intereses del conjunto de su población. Parte del medio ambiente y cuestiones relacionadas con derechos humanos están "regulados" principalmente por principios y directrices bajo el primado del softlaw. Son muchas las cuestiones que conviene tener en cuenta sobre si de verdad esta forma de regular funciona pero quizá convenga reflexionar sobre por qué son precisamente estos dos grupos de derechos tan sensibles los que más se ven afectados por este proceso mundial de desregulación.

Como ejemplo basta ver con qué impunidad Paraguay no lleva a la práctica el Convenio 169 de la OIT, obvia los Objetivos de Desarrollo Sostenible y desatiende las sentencias de la Corte IDH, que, por otro lado, se ha comprometido a respetar. Ello es posible, en parte, porque el control del cumplimiento con los métodos soft, como el informe de los observadores internacionales, no genera en el Estado un grado de vinculatoriedad suficiente o de exigencia. Por tanto, queda en manos del Estado decidir si respetan las directrices o no las respeta. 


\section{REFERENCIAS}

ÁNGEL CABO, N. La discusión en torno a las soluciones del softlaw en materia de responsabilidad social empresarial. Revista de Derecho Privado, (40), 3-37, 2006.

ANGUITA OYARZÚN, C. El rol del derecho en la responsabilidad social de la empresa. Arsboni et aequi, vol. 8, (1), 215-233, 2017.

ASÚNSOLO-MORALES, C.R. Los derechos humanos como límites al poder público y privado: otra vía de fundamentación. Dixi, vol. 17, (22), p. 95-106, 2015.

ATEHORTÚA HURTADO, F. A.Responsabilidad Social Empresarial: entre la ética discursiva y la racionalidad técnica. Revista EAN, (62), p. 125-140, 2008.

BAZ TEJEDOR, J. A. Empresa Socialmente Responsable y Derechos Fundamentales Laborales. Criterio Jurídico, vol. 7, 323-352, 2007.

BELLOSO MARTÍN, N. Algunos efectos perversos de la globalización: las empresas transnacionales y el deber de respeto de los estándares mínimos internacionales de derechos humanos. Cuadernos Electrónicos de Filosofía del Derecho, (28), p. 1-35, 2013.

DALLA-CORTE CABALLERO, G. Redes y organizaciones sociales en el proceso de ocupación del Gran Chaco. Revista de Indias, vol. LXVII, (240), p. 485-520, 2007.

DÁVALOS, P. No podemos ser mendigos sentados en un saco de oro: Las falacias del discurso extractivista. En J. Cuvi, D. Machado, A. Oviedo, N. Sierra (Coords.), El correísmo al desnudo, p. 190-215. Quito: Arcoiris Producción Gráfica, 2013.

DOBRÉE, P. El derecho a la tierra. Perspectivas para el análisis. En P. Dobrée (Coord.), La tierra en el Paraguay: de la desigualdad al ejercicio de los derechos, p. 1-13. Asunción: Programa Democratización y Construcción de la Paz ICCO, 2013.

ELÓSEGUI ITXASO, M. El concepto jurisprudencial de acomodamiento razonable: el Tribunal Supremo de Canadá y el Tribunal Europeo de Derechos Humanos ante la gestión de la diversidad cultural y religiosa en el espacio público. Anuario de filosofía del derecho, (30), p. 69-96, 2014.

ELÓSEGUI ITXASO, M. El libro verde de la RSC de la Comisión Europea y la teoría de los stakeholders desde la perspectiva de género. Cuadernos Electrónicos de Filosofía del Derecho, (21), 1-38, 2010.

GARRIDO GÓMEZ, I. El softlaw como fuente del derecho extranacional Madrid: Dykinson, S.L., 2017.

GUDYNAS, E. Conflictos y extractivismos: Conceptos, contenidos y dinámicas. Decursos. Revista en Ciencias Sociales, Año XV, (27-28), p. 79-116, 2013.

GUDYNAS, E. Diez tesis urgentes sobre el nuevo extractivismo. Extractivismo, política y sociedad, vol. 187, 2009. 
GUDYNAS, E. El nuevo extractivismo progresista en América del Sur tesis sobre un viejo problema bajo nuevas expresiones. En Colonialismos del siglo XIX. Vol. 21, p. 75-92, 2011.

GUDYNAS, E. Estado compensador de nuevos extractivismos. Las ambivalencias del progresismo sudamericano. Nueva Sociedad, (237), 2012.

LIZCANO, J.L. Buen gobierno y responsabilidad social. Partida doble, vol.182, p. 20-35, 2006.

MARTÍN-CABELLO, A. Sobre los orígenes del proceso de globalización. Methaodos. Revista de ciencias sociales, vol. 1, (1), p. 7-20, 2013.

MARTÍNEZ ALIER, J. Conflictos ecológicos y justicia ambiental. Papeles, (103), p. 11-27, 2008.

MARTÍNEZ ALIER, J.; WALTER, M. Metabolismo social y conflictos extractivos. En B. Hogenboom, M. Baud. F. de Castro (Editores). Gobernanza ambiental en América Latina, p. 73-104. Buenos Aires: CLACSO, 2015.

MERELESDUARTE,W.M.;GONZÁLEZCANTERO, M. A. Definición de la Matriz Energética de la República del Paraguay. Revista Científica Politécnica FPUNE Scientific, vol.3, (3), 51-56, 2014.

MORENO RODRÍGUEZ, J. A. El debate sobre el derecho no estatal y la lexmercatoria. Revista de Derecho Forseti, vol. 1, p. 74-97, 2014.

ORTEGA, G. Extractivismo en el Chaco paraguayo: Un estudio exploratorio. Asunción: BASE Investigaciones Sociales, 2013.

RODRÍGUEZ GARAVITO, C. Extractivismo versus derechos humanos: crónicas de los nuevos campos minados en el Sur Global.Buenos Aires: Siglo Veintiuno Editores, 2016.

ROJAS VILLAGRA, L. La tierra en disputa: Extractivismo, exclusión y resistencia. Asunción: BASE IS, 2014.

SOLEDAD DA COSTA, N. Conflictos por la regulación de la propiedad de la tierra en Paraguay. Tesis doctoral. Pontificia Universidad Católica de Chile, 2017.

STOKER, G. El buen gobierno como teoría: cinco propuestas. Revista Internacional de Ciencias Sociales, vol. 155, p. 3-35, 1998. 


\section{INFORMES OFICIALES}

Coordinadora de Derechos Humanos del Paraguay. Situación de los derechos a la tierra y al territorio de los pueblos indígenas en el Paraguay (s.f.). Recuperado el 21 de agosto de 2018 de: http://www.tierraviva.org.py/wp-content/uploads/2015/02/ Situaci\%C3\%B3n-de-los-derechos-a-la-tierra-y-al-territorio-de-los-pueblosind\%C3\%ADgenas-en-el-Paraguay-11.pdf.

Corte IDH. Informe actividad 2017 (s.f.). Recuperado el 31 de agosto de 2018 de http:// www.corteidh.or.cr/informe-anual.html.

Dirección General de Estadística, Encuestas y Censos. Censo de comunidades de los pueblos indígenas. Resultados finales 2012 (s.f.). Recuperado el 12 de mayo de 2018 dehttp://www.dgeec.gov.py/Publicaciones/Biblioteca/triptico\%20comunitario/ Triptico\%20censo\%20comunitario_Castellano.pdf.

IEEE/García Tasich (s.f.).Recursos naturales estratégicos. Recuperado el 2 de julio de 2018 dehttp://www.ieee.es/Galerias/fichero/docs_opinion/2017/DIEEEO38-2017. Recursos_Naturales_Estrategicos_SaraGarciaTasich.pdf.

IEEE/Tapia Ramírez, Isidoro (s.f.). La política energética de los EE.UU. y sus implicaciones geoestratégicas. Recuperado el 4 de julio de 2018 de http://www.ieee.es/Galerias/ fichero/cuadernos/Energia_Geoestrategia_2017.pdf

OMAL/Teitelbaum, Alejandro (s.f.). Empresa transnacional. Recuperado el 29 de noviembre de 2017 dehttp://omal.info/spip.php?article4802.

ONU/ Anaya (s.f.), Report of theSpecialRapporteurontheRights of IndigenousPeoples: Extractive Industries and IndigenousPeople, UN Doc, A/HRC/24/41. Recuperado el 30 de enero de 2018 dehttp://unsr.jamesanaya.org/docs/annual/2013-hrc-annual-report-en.pdf.

\section{NORMATIVA Y JURISPRUDENCIA}

Anexo Decreto N6092/2016 de la Política Energética dela República del Paraguay. Asunción: Congreso de la Nación Paraguaya, 2016.

Constitución del Paraguay. Asunción: Asamblea Nacional del Paraguay, 1992.

- CAPÍTULO V. De los Pueblos Indígenas.

- Art. 116 de Los latifundios improductivos.

- Art. 128 de La primacía del interés general y del deber de colaborar. 
Corte IDH. Casos de las Comunidades Indígenas Yakye Axa, Sawhoyamaxa y XákmokKásek Vs. Paraguay. Supervisión de Cumplimiento de Sentencia. Resolución de la Corte Interamericana de Derechos Humanos de 30 de agosto de 2017.

Corte IDH. Caso Comunidad Indígena XákmokKásek Vs. Paraguay. Fondo, Reparaciones y Costas. Sentencia de 24 de agosto de 2010. Serie C No. 214.

Corte IDH. Caso Comunidad Indígena Sawhoyamaxa Vs. Paraguay. Fondo, Reparaciones y Costas. Sentencia de 29 de marzo de 2006. Serie C No. 146.

Corte IDH. Caso Comunidad Indígena Yakye Axa Vs. Paraguay. Fondo Reparaciones y Costas. Sentencia de 17 de junio de 2005. Serie C No. 125.

Ley 60/90 del Régimen de Incentivos Fiscales para la inversión de capital de origen nacional y extranjero.

Ley 117/91 de Inversiones. Asunción: Congreso de la Nación Paraguaya, 1991.

Ley 779/95 de Hidrocarburos. Asunción: Congreso de la Nación Paraguaya, 1995.

Ley 1064/97 del Régimen de Maquila. Asunción: Congreso de la Nación Paraguaya, 1997.

Ley 5259/04 Concesión Hidrocarburos Chaco. Asunción: Congreso de la Nación Paraguaya, 2004.

Ley 2658/05 Concesión Amerisur. Asunción: Congreso de la Nación Paraguaya, 2007.

Ley 3479/07 Concesión Pirity Hidrocarburos SRL (Adquirida por PresidentEngergy). Asunción: Congreso de la Nación Paraguaya, 2007.

Ley 5258/14 Concesión Concesión Empresa Rivera S.A. Asunción: Congreso de la Nación Paraguaya, 2014.

Ley 5515/15 Concesión MB Energía S.A. Asunción: Congreso de la Nación Paraguaya, 2015.

Ley 5761/16 Concesión ZEUS ÖL S.A. Asunción: Congreso de la Nación Paraguaya, 2016. 